\section{Current Issues}

Check for updates

\title{
Overview of Postpartum Hemorrhage Project
}

\section{Sukhee Ahn $\mathbb{D}$}

Professor, College of Nursing, Chungnam National University, Daejeon, Korea

Keywords: Postpartum Hemorrhage; Prevention; Management

\section{BACKGROUND}

Obstetric hemorrhage is the most frequent cause of maternal morbidity and preventable mortality worldwide. The number of maternal deaths related to disease during pregnancy and delivery was 28 in Korea in 2017. Of them, 22 died of obstetric embolism, postpartum hemorrhage, or hypertension disorder as a direct cause of obstetric mortality [1]. In the United States, the rate of postpartum hemorrhage ( $\mathrm{PPH}$ ) increased 26\% between 1994 and 2006 (from 2.3\% to 2.9\%) in all women who gave birth primarily because of increased rates of uterine atony [2]. However, obstetric hemorrhage deaths may be preventable because women who die from $\mathrm{PPH}$ do not receive early, effective, and aggressive lifesaving treatments. Therefore, professional groups including the American College of Obstetricians and Gynecologists (ACOG) and Association of Women's Health, Obstetric, and Neonatal Nurses (AWHONN) are working to improve recognition, readiness, and response to postpartum hemorrhage [3,4]. This paper will introduce ACOG's Practice Bulletin to discuss risk factors for PPH as well as its evaluation, prevention, and management. It will also introduce AWHONN PPH project to improve maternal lifesaving and health outcomes.

\section{ACOG'S PRACTICE BULLETIN}

The ACOG has published ACOG Practice Bulletin to provide clinical management guidelines for $\mathrm{PPH}$ for obstetricians and gynecologists [3]. ACOG's reVITALize program redefines PPH as a cumulative blood loss greater than or equal to $1,000 \mathrm{~mL}$ or blood loss accompanied by signs or symptoms of hypovolemia within 24 hours after the birth process regardless of the route of delivery [5]. It is different from traditional definition of PPH as an estimated blood loss in excess of 500 $\mathrm{mL}$ after a vaginal birth or a loss of greater than $1,000 \mathrm{~mL}$ after a cesarean birth [6]. However, this new definition is supported by one retrospective study showing that blood loss using objective measures is more similar than perceived measures by obstetric providers between vaginal delivery and cesarean delivery [7].

Active management for PPH during third stage of labor can reduce the risk of severe primarily $\mathrm{PPH}$ greater than $1,000 \mathrm{~mL}$ at the time of birth from a Cochrane review [8]. However, it is not certain because the quality of evidence is low. Health care providers should regularly conduct maternal 
risk assessment at prenatal check, at admission, and during labor or postpartum period. Earlier recognition of PPH should be the first action to improve maternal health outcomes. Therefore, multidisciplinary work groups of the National Partnership for Maternal Safety have developed consensus maternal safety bundles on obstetric hemorrhage: readiness, recognition, prevention, response, reporting, and system learning [9].

\section{AWHONN'S POSTPARTUM HEMORRHAGE PROJECT}

With the same concern about maternal mortality for PPH, the American AWHONN has performed a PPH prevention project for AWHONN's obstetrical hemorrhage quality improvement initiative [10]. Many clinicians commonly use imprecise and inaccurate method of visual estimation of blood loss (EBL) at obstetric settings. However, the inaccuracy of EBL results in underestimation of blood loss by $33-50 \%$ [11]. A leading cause of preventable maternal mortality is failure to recognize or late recognition of excessive blood loss during childbirth. Thus, accurate and timely recognition of excessive blood loss is critical for early initiation of effective interventions. The AWHONN recommends that quantification of blood loss is a direct and objective method used to evaluate excessive bleeding [4]. Methods to quantify blood loss such as utilizing calibrated under-buttocks drapes, using gravimetric method (weigh all of materials that used to absorb the blood before and after), and laboratory analysis are significantly more accurate than EBL [12].

AWHONN also proposes PPH education modules consisting PPH management, team debriefing, simulation-based training for readiness, quantification of maternal blood loss, PPH risk assessment, maternal warning signs for recognition, and transfusion therapy for response [10]. Methods of education are via on-line, self-paced, and team training. For PPH projects, interdisciplinary expert panel runs PPH project at three selected states with the following criteria: high rates of maternal mortality, well-organized communication networks, and no competing obstetric hemorrhage-related initiatives in the state and strong AWHONN leadership. The PPH project algorithm has five stages of hemorrhage. Each stage is based on the amount of quantified blood loss. AWHONN recommends stage specific actions. Nurses and team members can study AWHONN quantification of blood loss practice brief, watch 3-minute video for quantification of blood loss via YouTube [13], and take on-line PPH education modules for obstetric patient safety.

\section{CONCLUSION}

Maternal mortality ratio in Korea was 7.8, higher than OECD of 6.8 per 100,000 live births. This is caused by increasing number of women with high-risk pregnancy and disproportional distribution of medical facilities to response to emergent situation. To solve these problems, the Korean government has launched comprehensive care for high-risk pregnancy in order to improve maternal and neonatal health outcomes.

The current big movement in America is to prevent and early detect PPH which is the major cause of maternal mortality. Maternal safety bundle for hemorrhage management at delivery proposed by the American College of Obstetricians and Gynecologists and guideline for quantification of blood loss at PPH proposed by the American AWHONN are reviewed. It provides useful information to perform evidence-based preventable nursing practice in Obstetric nursing area. Quality improvement project based on that guideline is necessary for maternal health practice. 


\section{REFERENCES}

1. Statistics Korea. 2017 Infant and maternal mortality [Internet]. Seoul: Statistics Korea; 2017 [cited 2018 Sep 1]. Available from: http://www.index.go.kr/potal/main/EachDtlPageDetail.do?idx_cd=2769.

2. Callaghan WM, Kuklina EV, Berg CJ. Trends in postpartum hemorrhage: United States, 1994-2006. American Journal of Obstetrics \& Gynecology. 2010;202(4):353.e1-353.e6. PUBMED | CROSSREF

3. Committee on Practice Bulletins-Obstetrics. Practice bulletin No.183: postpartum hemorrhage. Obstetrics and Gynecology. 2017;130(4):e168-e186.

PUBMED | CROSSREF

4. Quantification of blood loss: AWHONN practice brief number 1. Journal of Obstetric, Gynecologic and Neonatal Nursing. 2015;44(1):158-160. PUBMED | CROSSREF

5. Menard MK, Main EK, Currigan SM. Executive summary of the reVITALize initiative: standardizing obstetric data definitions. Obstetrics and Gynecology. 2014;124(1):150-153. PUBMED | CROSSREF

6. Dahlke JD, Mendez-Figueroa H, Maggio L, Hauspurg AK, Sperling JD, Chauhan SP, et al. Prevention and management of postpartum hemorrhage: a comparison of 4 national guidelines. American Journal of $\mathrm{Ob}$ stetrics and Gynecology. 2015;213(1):76.e1-76.e10. PUBMED | CROSSREF

7. Hamm RF, Wang EY, Bastek JA, Srinivas SK. Assessing reVITALize: should the definition of postpartum hemorrhage differ by mode of delivery? American Journal of Perinatology. 2017;34(5):503-507. PUBMED | CROSSREF

8. Begley CM, Gyte GM, Devane D, McGuire W, Weeks A, Biesty LM. Active versus expectant management for women in the third stage of labour. Cochrane Database of Systematic Reviews. 2019;2:CD007412. PUBMED | CROSSREF

9. Main EK, Goffman D, Scavone BM, Low LK, Bingham D, Fontaine PL, et al. National partnership for maternal safety: consensus bundle on obstetric hemorrhage. Obstetrics and Gynecology. 2015;126(1):155162. PUBMED | CROSSREF

10. Association of Women's Health, Obstetric and Neonatal Nurses (US). 2018 Maternal mortality resources [Internet]. Washington, D.C.: Association of Women's Health, Obstetric and Neonatal Nurses; 2018 [cited 2018 Aug 15]. Available from: https://www.awhonn.org/page/MaternalMortalityRes.

11. Patel A, Goudar SS, Geller SE, Kodkany BS, Edlavitch SA, Wagh K, et al. Drape estimation vs. visual assessment for estimating postpartum hemorrhage. International Journal of Gynaecology and Obstetrics. 2006;93(3):220-224. PUBMED | CROSSREF

12. Al Kadri HM, Al Anazi BK, Tamim HM. Visual estimation versus gravimetric measurement of postpartum blood loss: a prospective cohort study. Archives of Gynecology and Obstetrics. 2011;283(6):1207-1213. PUBMED | CROSSREF

13. Association of Women's Health, Obstetric and Neonatal Nurses (US). Quantification of blood loss video [Internet]. Washington, D.C.: Association of Women's Health, Obstetric and Neonatal Nurses; 2014 [cited 2018 Aug 16]. Available from: https://www.youtube.com/watch?v=F_ac-aCbEn0\&list=UUPrOhL3Od7ZeFDq27ycS00g. 